\title{
La traducción teatral contemporánea: ¿una traducción literaria, escénica, sociodiscursiva, corporal? Ilustración a través de Juste la fin du monde de Jean-Luc Lagarce
}

\author{
CRISTINA VINUESA \\ Universidad Complutense de Madrid \\ cvinuesa@filol.ucm.es
}

Recibido: 10 de noviembre de 2012

Aceptado: 30 de marzo de 2013

\section{RESUMEN}

Este estudio viene, a modo de testimonio, presentar el peculiar trabajo del traductor teatral contemporáneo. En primer lugar, hace especial hincapié en la labor de investigación que desempeña el traductor por descubrir nuevos textos desde los teatros y no desde la posible publicación de éstos, ya que los textos dramáticos de nuestro siglo, están pensados, elaborados y escritos mayoritariamente desde la escena. Esta búsqueda conlleva a la par, una investigación in situ pero además un porcentaje de casualidad y oportunidades. En segundo lugar, se trata de mostrar mi propia trayectoria: una experiencia como actriz, enriquecida por una formación filológica. Una combinación de experiencia interpretativa, complementado por una sensibilidad teórica literaria. En tercer y último lugar, desarrollo el procedimiento de la traducción desde el texto como materia "horizontal" y dramática, hasta su puesta en escena o "verticalización" dramatúrgica, de una obra contemporánea francesa: Juste la fin du monde (Tan solo el fin del mundo) de Jean-Luc Lagarce.

Palabras clave: Dramaturgia, puesta en escena, representación, traducción teatral, verticalización.

The contemporary theatrical translation: literary translation, scenic, social-discursive, corporal? Illustration through Juste la fin $d u$ monde by Jean-Luc Lagarce
ABSTRACT
This essay, stemming from my personal experience, endeavours to present the complex work of contemporary drama translator. First, it deals with the preliminary research lead by the 
translator in order to discover new texts for the stage and not for publication, as dramatic texts nowadays are mainly conceived and written for the stage. This research process involves also a great deal of casualty and hazard. Then, it shows my personal experience as a translator which began with an experience as an actress and was followed by a university career in drama and literature. Third, it presents the process of drama translation as a "horizontal", dramatic work which, once on stage, becomes "vertical" or dramaturgical, by showing the case study of the translation of Juste la fin du monde (It's only the End of the World) by Jean-Luc Lagarce.

Keywords: dramaturgy, staging, representation, theatrical translation, verticality.

Sumario: 1. Un panorama complejo. 2. Una trayectoria como cualquier otra. 3. Juste la fin $d u$ monde... ¿Tan solo el fin del mundo? 4. Conclusión.

Al reflexionar sobre la peculiaridad de traducción teatral, enseguida me asaltaron tres preguntas: ¿cómo sintetizar mi experiencia como traductora de teatro?, ¿es posible esquematizar de forma más general la traducción teatral contemporánea? Y por fin, ¿cómo voy a poder hablar de mis traducciones sin los actores o el director? Y seguidamente, al buscar el por qué de estas súbitas interrogaciones, me di cuenta de que hasta ahora y sin realmente darme cuenta, veía mi papel de traductora como una herramienta invisible, el mero eslabón de una cadena de procesos creativos en los que mi función consistía en facilitar relaciones entre personas: actores con personajes, autores con directores, y cosas: textos con escenarios, espacios con otros. De hecho, casualmente el adjetivo invisible, apareció días mas tarde, al leer la reflexión de Antonio Muñoz Molina acerca de los traductores:

Lo fundamental tiende a ser o a volverse invisible. Porque son fundamentales y porque su trabajo está en todas partes, los traductores tienden a desvanecerse en la invisibilidad, y también porque cuando mejor hacen su oficio, menos huellas quedan de él, hasta el punto de que parece que no haya intervenido. $[\ldots]^{1}$

Trataré pues, de quitarme la capa de invisibilidad como cual héroe juvenil cinematográfico, y compartiré con ustedes algunas de las reflexiones que surgieron a raíz de la preparación de este trabajo. Tras intentar dibujar brevemente en un primer momento, el mapa de la situación de la traducción teatral en España, incluyendo la sobretitulación, reuniré todas las piezas de mi particular puzzle profesional de docente-traductora-actriz-directora, para estudiar más concretamente la historia de una obra desde su traducción hasta su representación: se trata de Juste la fin du monde, del dramaturgo francés Jean-Luc Lagarce.

${ }^{1}$ MuÑoz Molina, A., Los traductores. El pais, 29/09/12. http://cultura.elpais.com/cultura/ 2012/09/26/actualidad/1348657096_697540.html 


\section{Un panorama complejo}

Tanto para convertirse en un traductor generalista como especializado (sean traducciones literarias, filosóficas, técnicas, comerciales, financieras, jurídicas, científicas, biomédicas, farmacéuticas, audiovisuales o multimedial) existe una formación académica oficial, reconocida y en consecuencia, cabe pensar que es lo normal poder optar por una planificación previa. He oído a menudo gente decir: quiero o sueño con ser traductor, y de ahí, estos estudiantes iniciaban la carrera correspondiente. Sin embargo, cuando uno se encuentra con un traductor teatral, suele ocurrir, que se haya hecho traductor así, sin pensarlo realmente, sin más, como un fruto del azar, porque surgió tras un encuentro con un autor, unos amigos actores, un festival. La idea de traducción teatral y más, contemporánea, no suele preverse, aparece como un juego, como un ¿por qué no lo intento? Por experiencia, creo que el traductor teatral no nace, ni se hace, sino que surge de la conjunción de variables casuales. Y sino, leamos la respuesta que dio el consagrado traductor de teatro contemporáneo francés Fernando Gómez Grande, a la sencilla pregunta de ¿Por qué elegir la traducción teatral y por qué el teatro contemporáneo? Es un fragmento de una entrevista realizada por Emmanuelle Garnier (profesora de la Universidad Toulouse II Le Mirail) en unas jornadas sobre la traducción que tuvo lugar en 2011:

E. G: ¿Cómo llegaste a traducir teatro francés por una parte y contemporáneo? F.G.G: Uno nunca sabe muy bien porque llega a hacer las cosas, sino que es una especie de combinación de deseo y azar. Hay encuentros o algún azar en algún momento que te lleva y te conduce a un camino que no estaba previsto. Hay encuentros fortuitos y casualidades del azar que hacen que en un momento alguien me dijo, por qué no te lanzas a esto (no hay muchos traductores de teatro). Te pilla de sorpresa. En este caso fue Rodolf Sirera en Valencia, que me sugirió traducir a 4 autores franceses para que se publicaran en un volumen. $[\ldots]^{2}$

A Fernando Gómez Grande, le gustaba el idioma y el teatro. Ésa es la segunda condición sine cua non para traducir teatro, te tiene que gustar el teatro. Parece una obviedad, pero no lo es tanto si uno no considera el teatro como un género independiente de la literatura. El arte dramático conlleva una serie de elementos más allá de la faceta filológica que hay que tener muy en cuenta a la hora de traducir. Un texto teatral es básicamente una partitura con espacio, tiempo y personajes concretos, es un volumen que toma forma y sentido en su escenificación, en su verticalización. Por eso, traducir teatro, es además de trasladar de una lengua a otra una historia, construirle a esta historia un espacio adecuado, para que se pueda oír y ver. Y por ello, muchas veces, un traductor de teatro suele ver mucho teatro para nutrir su imaginación escénica, incluso haber probado alguna clase de interpretación en algún

2 http://www.canal-u.tv/video/vo_universite_toulouse_le_mirail/entretien_avec_fernando_gomez grande.6773 (1-02-11) 42 min. Entrevista echa por Emmanuelle Garnier Profesora de la Universidad Toulouse II-Le Mirail. 
momento y haber frecuentado gente "del mundillo". Por eso, la función de traductor teatral suele improvisarse: surge, e incluso se impone de manera inesperada tras el impacto causado por un espectáculo, una charla con algún amigo autor empeñado en llevar su obra mas allá de sus fronteras, o un proyecto entre amigos actores, ansiosos por descubrir nuevos textos. El traductor de teatro contemporáneo es una persona del presente y de acciones, alguien que está sin casi saberlo, en medio de la gente y de un proceso creativo en el que colabora con sus dotes lingüísticas y creativas.

E insisto en la noción de improvisación, y no solo porque tenga la palabra un matiz teatral en si, sino también porque en el mundo laboral de la traducción teatral, lo incierto predomina por encima de todo. Decía Ionesco: "Coge un círculo, acarícialo y se convertirá en un círculo vicioso", pues es exactamente lo que ocurre con las traducciones teatrales contemporáneas... Si ves una obra extranjera puede que quieras leerla a posteriori, pero si no la lees, puede que no sepas que existe y en consecuencia, no vayas a ver su representación escénica... Y así es como funciona el mundo teatral. Un manuscrito de teatro traducido, puede circular de teatro en editorial y viceversa, hasta que uno de los dos decida apostar por él. La publicación teatral contemporánea internacional es escasa, al menos en Madrid y su representación puntual (Festival de otoño, sección una mirada al mundo). La difusión y comercialización son mas bien precarias salvo en aquellos teatros públicos que organizan festivales internacionales (Los CDN, El teatro español y el Matadero, La cuarta pared y los teatros del Canal). Se salvarán los grandes éxitos e incluso se llevarán a la gran pantalla como es el caso de Y. Reza con un Dios salvaje. Pero aún así, ¿Quién se compra el texto una vez vista la obra? La fragilidad y la riqueza de la traducción teatral vienen en parte de su carácter efímero y presente. Existen varias razones por las que uno emprende una labor de traducción (¿flechazo? ¿casualidad?) y una vez concluidas, pueden evolucionar de forma muy diferente. Se puede traducir por simple placer como nos decía Fernando Gómez Grande y acumular tesoros en el fondo de un cajón. En ese caso, pueden permanecer en el olvido, pero si el traductor es tenaz y cree en su potencial escénico, también puede decidir difundirlo en su entorno y acabar en representación sin ánimo de lucro. También por último, es posible que se represente con ánimo de lucro y que entre en el circuito oficial y reconocido y entonces, el traductor tiene que contactar con el autor, obtener los derechos de traducción y si lo desea, firmar una exclusividad de traducción para proteger su trabajo. Esta opción, es la opción que más favorecerá la publicación de la traducción. El problema es que una obra contemporánea suele verse primero y luego quizás, se compra, si realmente ha gustado el texto o si el autor se ha convertido en un "clásico contemporáneo".

Fernando Gómez Grande que cuenta con mas de 100 obras traducidas a autores franceses de mayor reconocimiento me confesaba al hablar de la situación actual:

La situación actual es compleja. Sobre todo la de la traducción teatral y en una lengua «próxima» como el francés. Los autores contemporáneos franceses, excepto honrosas excepciones desde terrenos más asequibles y de éxito internacional como Y. Reza, Eric-Emmanuel Schmitt y poco más, o desde terrenos más en la 
línea de los teatros públicos, no son muy apreciados en España. Es difícil encontrar en nuestra cartelera esos nombres que hacen y llenan teatros públicos y festivales en Francia. En novela se traduce algo más, [...] en nuestro país, pero igual y fundamentalmente novelas o narraciones de éxito asegurado ${ }^{3}$.

En conclusión, diría que el traductor teatral cae en la traducción porque se ha enamorado de un texto, porque tiene fe en su potencial escénico, y fe en alguna compañía y/o un teatro que crean en el texto. No nos engañemos, tendrá mas probabilidad de existir en otro país, si el texto original ya se ha representado con éxito, o si ha sido premiado. Y solo después de este épico recorrido, se podrá quizás pensar en alguna recompensa económica... Las ayudas públicas (en España) siguen siendo casi inexistentes y los autores contemporáneos no consagrados no pueden remunerar satisfactoriamente a sus traductores. Entonces se preguntarán ¿por qué traducir teatro si eres invisible, trabajas gratuitamente la mayor parte del tiempo, y si tampoco sabes si la obra va a funcionar? Es cierto que traducir teatro contemporáneo es un riesgo, siempre, pero precisamente por eso, tiene ese atractivo y también porque es una aventura humana donde la imaginación y el sueño son los protagonistas, y si algún día se materializa ese sueño, tiene un valor inestimable. Por eso, se apuesta por ello.

\section{Una trayectoria como cualquier otra}

Para confirmar lo planteado en la introducción, qué mejor que resumir en pocas palabras mi encuentro casual, como no, con la traducción teatral. Hacía teatro en París en una compañía de teatro contemporáneo llamada La Compagnie du Goudron et des Plumes dirigida por Mariapia Bracchi, interesada en representar obras recientes europeas. Me pidieron consejo sobre algún texto contemporáneo español. $\mathrm{Me}$ vine a Madrid y empecé a leer obras hasta que me gustara realmente una de ellas. Seleccioné Los enfermos ${ }^{4}$ de Antonio Álamo. Llegué a Paris, empecé a traducir un fragmento, un par de escenas y en cuatro meses, había traducido la obra entera. Contacté al autor, conseguí su autorización y pudimos, montar la obra en 2003. Desde entonces, traduzco obras de teatro del español al francés y del francés al español, soy miembro del comité hispánico de la Casa Antoine Vitez, institución teatral francesa que se dedica a descubrir y difundir en Francia textos dramáticos extranjeros, también actúo de vez en cuando, y últimamente dirijo cuando puedo. Mi principal motivación en el caso de Los Enfermos, fue trasladar a escena un texto leído para darles vida a los personajes: era actriz y me apetecía actuar.

Ese volumen textual traducido, coincide con la reflexión que plantea Henri Meschonnic en La critique du rythme: [...] sobre la traducción: "Se debe hacer oír lo que no se lee". Y añadiría, y hacer ver que no se lee. El traductor teatral debe ver, oír el

\footnotetext{
3 Entrevista a Fernando Gómez GRANDE, cedida vía mail, el 3 de octubre de 2012, a las 20:55.

4 Alamo, A., Les Malades. Besançon: Solitaires Intempestifs 2000.
} 
texto e imaginarse su representación. Desempeña una labor de director, escenógrafo y dramaturgo a la vez. Por eso, se tienen que tener en cuenta una serie de factores puramente dramatúrgicos. Existen claro está los factores dramáticos (historia y personajes) pero están sostenidos por los factores dramatúrgicos (el espacio, el tiempo, la caracterización de los personajes anotadas por el autor en las acotaciones, sus facciones, actitudes corporales, clase social, vestuario, cualquier pista de tipo dramatúrgica influye en el lenguaje y ritmo de la obra.). Se trata de una verdadera investigación dramatúrgica, se descodifican las pistas didascálicas para realizar el trabajo más fiel posible. Aunque seamos prudentes al usar la palabra fidelidad porque en teatro, es cierto que es primordial restablecer una fidelidad, pero en su conjunto. La fidelidad desde mi experiencia, se basaría más en el respeto del pensamiento de un autor, más que en su lenguaje. Nos acercaríamos más quizás a la idea de "incorporación de una dramaturgia". Por eso, muchas veces un traductor tiene a "sus" autores y maduran ambos, a medida que el primero escribe y que el segundo traduce. Lo que se acaba trasmitiendo es un pensamiento, una trayectoria. Cuánto más se conoce a un autor, más se le entiende, y menos probabilidades tienes de equivocarte o de alejarte de su teatro. También es importante señalar que la traducción teatral tiene que tener en cuenta una representación y en consecuencia, una recepción. Lo representan y lo ven personas en un determinado país y en una determinada época. Hay que ser consciente de que estamos ante un espectador potencial y no un lector. Por eso es fundamental, en la medida de lo posible, no perder de vista el presente como una realidad concreta incluso como un aliado, considerando los factores sociales y culturales tanto de la obra como de su posible público para optimizar la comprensión y el éxito de la traducción. Habría que preguntarse siempre: ¿A quién va dirigida la obra? ¿En qué contexto social y cultural se va a representar? ¿Desde donde la traduzco?

Dicho esto, entraremos de forma mas concreta en el trabajo de la traducción. La traducción teatral posee varias etapas. Se inicia en un primer momento, el trabajo de traducción del texto donde se tienen en cuenta todos los factores mencionados anteriormente (texto y acotaciones). A medida que se va traduciendo, se alternan frases escritas y leídas. Es imprescindible leer en voz alta cada una de las palabras y oraciones traducidas para ver como suenan, alternar oralmente el hipotexto y el hipertexto para vigilar de cerca el ritmo, los registros elegidos etc... Lo mas recomendable es incluso pedirles a los actores alguna lectura durante este proceso. Tras esta primera traducción- lectura, donde se prioriza el sentido y el ritmo, subyace otra labor más delicada que consiste en enfrentarse a las dificultades socioculturales de la obra. Esta etapa obligará al traductor a "elegir" y en consecuencia, a excluir. En efecto, cuando nos enfrentamos a obras especialmente "ancladas" en una época o una sociedad determinada, pueden surgir problemas de comprensión en juegos de palabras, chistes relacionados con acontecimientos propios del país o incluso referencias locales (referencias a barrios, o personajes televisivos). Cuando esto ocurre, existen dos opciones: o bien mantener el contexto original (nombres, calles, nombres de platos, bebidas locales etc), con el riesgo de que se pierdan en camino guiños del autor (referencias culturales, humor etc) o bien buscar una equivalencia al idioma de llegada para privilegiar el objetivo de establecer proximidad con el públi- 
co por ejemplo. Ahí aparecen casos como el de sustituir "el kir en Pigalle" por el "chato de vino en el rastro" por ejemplo. Surgió un caso parecido el año pasado, cuando en mi traducción de Cocina y Dependencias de Agnès Jaoui y Jean-Pierre Bacri una de las protagonistas Charlotte, encarga un postre típico francés une bûche de noël para unos amigos que había invitado a cenar una noche de junio. La gracia consistía en saber que la bûche es el típico postre navideño francés. Si decidía guardar el término original nadie lo entendería, de hecho, la actriz que encarnaba a Charlotte se sentía incómoda con la escena hasta que decidí sustituir la bûche por el roscón de reyes español. Así, cuando la actriz dijo: "Nadie ha probado el postre con lo original que era encargar un roscón de reyes helado en junio", suscitó el efecto cómico que tenía ese mismo gag en francés. En este caso, mi decisión fue salvar la escena con una equivalencia cultural. El traductor se enfrenta continuamente con este tipo de decisiones que puede tomar en solitario o consultarlo con el autor. Tras estas dos fases, aparece una tercera en la que se hace un primer balance contrastando con otro traductor, compartiendo las elecciones con el propio autor, incluso hablando con el director si se trata de un trabajo para un montaje. Esta fase es interesante porque se abren más puertas, más dudas, más interpretaciones y puede enriquecer la traducción. Lo que si quisiera señalar, es que en la traducción teatral contemporánea, siempre se está en contacto con los demás, es un trabajo colectivo, imaginativo, hasta físico. Una traducción teatral evoluciona y se retoca hasta el último momento. De hecho, pueden existir dos traducciones de una misma obra: la versión publicada y el manuscrito llevado a escena retocado, cortado o modificado por el director y los actores. Este último caso sucede durante las lecturas de mesas o ensayos. Puede que existan ligeras modificaciones en expresiones o giros, porque se prestan mejor a la puesta en escena. Esas modificaciones suelen ser mínimas pero sí necesarias, cuando ayudan al actor a construir su personaje o acompañan una expresión corporal específica.

Esto fue de hecho lo que sucedió en Los enfermos de A. Álamo, pero también aquel mes de agosto del 2009 cuando decidí traducir Juste la fin du monde, la obra mas emblemática de JLL. Lagarce. Aquel verano, estaba en la fase final de redacción de mi tesis doctoral sobre este mismo autor, y decidí antes de proseguir, comprobar "físicamente" mis hipótesis sobre la circularidad espacial, temporal, dramática y actancial, intentando montar este texto con actores españoles y presentarlo bajo una lectura dramatizada en el marco de la tercera edición del Festival Escenas de Noviembre que codirijo con el teatro del Astillero.

A continuación, intentaré resumir y destacar algunas reflexiones acerca del proceso de traducción, desde el texto original hasta su representación final.

\section{Juste la fin du monde... ¿Tan solo el fin del mundo?}

\subsection{Una escritura performativa y un polílogo sin movimiento corporal}

Ante todo, habría que hablar de J-L. Lagarce (1957-1995), como hombre y dramaturgo. Podría resumir brevemente su biografía y bibliografía de forma académi- 
ca, pero para eso está la editorial Les Solitaires Intempestifs que fundó su amigo François Berreur, y que tiene publicada la totalidad de su obra (teatro, diario, vídeos, libretos de ópera, ensayos). Prefiero mostrarle a través de una respuesta que dio a Jean-Michel Potiron en una entrevista, cuando éste le preguntó porque escribía teatro. Contestó lo siguiente:

Lorsqu'on a demandé à Beckett pourquoi il écrivait, il a répondu : « bon qu'à ça. » J'ai répondu une fois très sérieusement à cette question: je fais du théâtre pour ne pas être seul. Lorsque j'écris, je suis seul. [...] N'être pas tout seul, c'est raconter quelque chose avec les autres et pour les autres. [...] Tout se passe dans la tête. Je travaille au milieu d'une ruche et j'accomplis le meilleur travail lorsque je me sens tout seul dans ma tête au milieu de tout le monde, en osmose autour de moi ${ }^{5}$.

Cuando le preguntaron a Beckett porque escribía, contestó: "solo valgo para eso". Yo contesté a esa pregunta una vez muy seriamente: Hago teatro para no estar solo. Cuando escribo, estoy solo. [...] No estar solo, es contar algo con los demás y para los demás. [...] Todo ocurre en la cabeza. Trabajo en medio de una colmena y ejecuto el mejor trabajo cuando me siento solo en medio de todo el mundo, en osmosis alrededor mío.

[...] je fais du théâtre pour ne pas être seul. J-L. Lagarce se dedica al teatro para no estar solo: esto no revela necesariamente une reticencia a la soledad sino más bien una manera de posicionarse en el mundo y de concebir su relación con los demás. Y esta postura tendrá repercusiones en su escritura. J-L. Lagarce ha elegido el arte dramático para establecer una relación con el Otro. Es decir que concibe la relación social a través de un texto previamente escrito y una escena, como si hubiera una voluntad de integrar a la vida real, un juego que le perteneciera sin pertenecerle. Esto indicaría que vida y teatro compartirían un mismo escenario.

Esto plantaría dos peculiaridades. En primer lugar, si sabemos que el teatro es caracterizado por su función catártica, implicando para ello una disociación entre vida y teatro, ¿como puede implicar su vida en el teatro y liberarse o purgarse de ella simultáneamente? En el teatro de Lagarce, todos los elementos fusionan: espacio, tiempo, personas, personajes, reflexiones reales y ficticias, estableciendo así un teatro que cuenta, que reflexiona, que observa y que dice que reflexiona. En segundo lugar, afirma que cuando mejor escribe, es cuando "se siente solo en medio de los demás". Lagarce escribe reivindicando su soledad. Quiere que le oigan, no que le respondan. Asi es como crea una escritura del pensamiento individual. Los personajes hablan pero no dialogan. Especulan sobre lo que piensan los demás. No interesa la realidad sino la percepción que se tiene de cada uno, y la escritura plasma, esa percepción dirigida a un espectador/cómplice de ese lenguaje-pensamiento in vivo. Es una escritura compleja y performativa que quisiera destacar primero como

5 Textos inéditos de Jean-Luc Lagarce, publicados en la revista Europe, $n^{\circ}$ 969-970, enero-febrero 2010 , 150. Esos textos están sacados de los archivos de l'IMEC gracias a la colaboración y a la autorización de François Berreur. 
traductora, y luego como directora. A modo de ejemplo, citaré una réplica de la Madre del protagonista Louis en Juste la fin du monde:

Tu étais à peine arrivé tu pensais déjà que tu avais commis une erreur et tu aurais voulu aussitôt repartir. (JFM, p. 236)

Acababas de llegar y ya, pensabas que habías cometido un error y te hubieras querido marchar enseguida. (JFM, p. 35)

Detengámonos un momento en esta réplica: en un mismo enunciado, conviven el pluscuamperfecto (estabas pensando), el imperfecto (pensabas) y el imperfecto del subjuntivo (hubieras querido). Aparecen tres tiempos verbales yuxtapuestos que desvelan una tensión temporal que expresa simultáneamente el acontecimiento del regreso, atribuyéndole las modalidades subjetivas del remordimiento y del deseoremordimiento inmediato a la llegada del protagonista, de haber hecho lo que está hecho, regreso de la conciencia reflexiva del error cometido sin remedio, el deseo simultáneo de volver a irse, de deshacer lo que se ha hecho, y por último, la proyección fantasiosa de un regreso como acción, que permitiría dar media vuelta. Esta réplica es la perfecta ilustración de la escritura lagarciana, una epanortosis que consiste en retomar, corregir, reformular matizar un discurso, mostrar los recovecos del pensamiento, hacer fusionar una lengua y un pensamiento, materializándose en una performatividad escénica en una experiencia temporal autorreferencial. Por un lado, el espectador es testigo de un discurso fusional lenguaje-pensamiento, que invade el personaje que habla dentro de una temporalidad dramática, exponiendo el verdadero drama que parece estar más focalizado en el hecho de haber venido para anunciar su muerte, que la muerte en si. Es decir que predomina más el hecho de decir, que el propio enunciado y por otro lado, también nos situamos en una temporalidad real, ya que el locutor toma conciencia en ese preciso momento de la enunciación, lo comparte verbalmente y desarrolla su pensamiento in situ.

Hablando de enunciación, situemos la obra. Lagarce escribe Juste la fin $d u$ monde en el año 1989, año en el que vive en Berlín tras conseguir una beca de escritura y año sobretodo en que descubre con treinta y dos años, su seropositividad.

Antes de ese año determinante a todos los niveles, escribía teatro de carácter irónico, político con tintes filosóficos debido a su formación académica: a la vez que estudiaba interpretación en el conservatorio, cursaba brillantemente la carrera de filosofía en la Universidad. Admiraba a Beckett y Ionesco, y le gustaba reflexionar sobre las jerarquías sociales a modo de diálogos retóricos, vacíos de sentido y de humor absurdo. Execraba la vida burguesa provinciana y siempre que podía, denunciaba con mucho humor la ignorancia conservadora, y las mentes mezquinas del mundo occidental. Sus personajes representaban estatutos sociales "universales" (gobernadores, propietarios, sirvientes, etc) y aunque se fijara en los pequeños detalles, siempre servían para apoyar una reflexión general sobre las injusticias sociales y las relaciones abusivas de poder. En 1989, descubre que está enfermo de SIDA y sabe que va a morir. Es importante subrayar esto último, ya que la década de los ochenta en Francia, fue desgraciadamente recordada por la hecatombe debida al 
virus del SIDA. El tratamiento AZT llevaba solo dos años en vigor, y la "tri terapia" se creó en 1989 de forma experimental, de hecho, Lagarce se prestó voluntario para probar el tratamiento y sobrevivió cinco años más antes de sucumbir a la enfermedad. Esos cinco años de incertidumbre dieron sus obras maestras: Le Pays Lointain, Histoire d'amour (derniers chapitres) o Juste la fin du monde. Lagarce viene de una familia obrera, humilde y de creencia protestante, instalada en un pequeño pueblo del este de Francia. Siempre mostró un gran interés por la lectura. Niño dotado de una gran sensibilidad y muy inquieto, decidió alejarse muy pronto de una familia tradicional, estricta y poco habladora, para perderse y encontrarse en la urbe parisina. Su familia sabía de él lo que él quería comunicarles en breves conversaciones telefónicas, y desconocían totalmente su vida artística, su homosexualidad y sobre todo su enfermedad. A partir de esa ruptura, construye un círculo de amigos-actores con y para los que empieza a escribir y compartir ese teatro vital o esa vida teatral. Narra existencias que cruzan hábilmente anécdotas ficticias y reales, construye un teatro en trompe l'oeil donde conviven amores y desamores, que a la vez que se desarrollan en un tiempo dramático, se distancian en un tiempo real, conferido por esa escritura-pensamiento en construcción.

En 1989 empieza a escribir, consciente de su muerte próxima, Juste la fin du monde. Deja las temáticas universales para centrarse en el círculo familiar. Adopta un tono íntimo y grave, y escribe a modo de confesión, de grito, de desesperación, de juicio, una reflexión casi postmortem. Esta obra cuenta la historia de un chico de treinta y cuatro años de edad llamado Louis, que decide volver a la casa familiar un domingo, después de muchos años ausente, para anunciar su muerte próxima. No consigue su propósito ya que los miembros de la familia, sus dos hermanos pequeños, su madre y su cuñada, sorprendidos por esa visita inesperada, deciden decirle con vehemencia y cariño torpe, todo lo que callaron hasta ahora, y sintieron ante esa ausencia prolongada e inexplicada todos estos años. De forma brusca y balbuceante, expresan violentamente el sentimiento de abandono, rencor, tristeza y sufren del silencio de un hermano que huyó del círculo familiar. Es una parábola del hijo pródigo invertida, donde ni existe misericordia paterna, ni regreso redentor. Aquí, Louis no vuelve para hallarse sino para morir6.

Si hacíamos anteriormente hincapié en el aspecto performativo de una escritura construida en "tartamudeos" en el sentido Deleuziano de la palabra, (es decir que la fuerza del lenguaje surge del centro de las oraciones, de la discontinuidad, de la fragmentación del pensamiento en movimiento y autorreflexión y autocorrección), el segundo aspecto de la escritura lagarciana que resaltaré al hablar de la traducción, es el aspecto monologal e "intelectual" de su teatro. Lo que vemos y oímos en el escenario no son historias sino, pensamientos ocupando y atravesando cuerpos. Estamos ante un teatro donde surgen voces en paralelo y no transversales. El espectador recibe polílogos para retomar el concepto de J. Kristeva, que son (in)directamente dirigidos del escenario al público, mostrando como decía el pro-

6 "[...] porque este tu hermano estaba muerto y ha vuelto a vivir; estaba perdido y ha sido hallado." Lucas $42: 15: 11 ; 42: 15: 32$. 
pio autor, "una soledad en medio de los demás". Es una obra donde la palabra es el cuerpo, el movimiento y el pensamiento a la vez. La complejidad del lenguaje-pensamiento performativo, la ambigüedad de un teatro que oscila continuamente entre ficción y realidad, y el falso estatismo de una palabra en continua reformulación, fueron los motivos que me llevaron al intento de traducción y montaje de dicha obra. Este movimiento verbal provocó más dificultades escénicas que problemas de traducción.

\subsection{Unos ensayos, no sin dificultades}

La estructura de un lenguaje "tartamudeante", un texto dramático polilogal y una temática potente fueron las razones que me condujeron a emprender la traducción de esta obra, fue el reto lingüístico y dramático que obstaculizó a menudo su realización y montaje. Siguiendo los siete puntos que determinan el modelo de la teoría funcional de traducción o teoría del Skopos de Hans Josef Veermer ${ }^{7}$ es decir los siete factores que intervienen en el proceso de traducción:

1) el traductor/

2) el proceso de traducción con su fase hermenéutica y de reexpresión/

3) el emetor/

4) la comunicación (contexto sociocultural, el impacto)/

5) el tipo de texto (informativo, persuasivo o expresivo, multisemiótico/

6) el receptor

7) la transferencia (equivalencia, selección y jerarquía)],

podríamos afirmar con casi total seguridad, que la dificultad de traducción no radicaba ni en la fase de comprensión, ya que el registro lagarciano es bastante sencillo, ni en la recepción, ya que se trataba de una obra contemporánea que, en su versión original conoció y conoce un éxito notable. Por otra parte, la época y el tiempo en los que se desarrolla la historia son actuales, y la obra responde a un esquema familiar occidental. El contexto cultural tenía fácil solución de equivalencia, y los personajes carecían de peculiaridades culturales o sociales marcadas. Aparecen la madre, el hijo mayor, el hermano, la hermana y la cuñada. La dificultad se centraba en el punto seis: el tipo de texto y el análisis previo de éste, antes de emprender el propio trabajo de traducción. Juste la fin du monde se encuentra en la intersección de un texto poético, persuasivo y expresivo. La circularidad del pensamiento de los personajes responde a una estructura que obliga a replantearse constantemente la elección del traductor.

En efecto, la escritura lagarciana responde a un esquema muy preciso que había que respetar escrupulosamente sino, la belleza y eficacia escénicas fracasaban. Al iniciar el discurso, cada personaje tiene un objetivo informativo claro

\footnotetext{
${ }^{7}$ ReISS / VeERMER 1991, 11.
} 
(cada uno quiere decir algo concreto y simple: te odio, por qué me juzgáis etc...): fase uno. El personaje intenta formular ese mensaje pero al no encontrar la palabra, la expresión o el tiempo verbal adecuados, llega a una multitud de rodeos sintácticos, gramaticales y léxicos altamente estudiados y matizados: esa búsqueda en vano de la palabra perfecta o más ajustada al pensamiento inicial seria la fase dos. Al fin, tras una larga digresión, el personaje no consigue su propósito, y vuelve a la frase inicial o pensamiento inicial sin haber podido desarrollar su pensamiento: es la fase tres.

Este esquema confirma lo que vimos anteriormente, prevalece más el como decir que lo dicho. Toda la riqueza y la dificultad del lenguaje de Lagarce es precisamente traducir todos esos intentos, que revelan mucho más que el pensamiento primero. Esta estructura circular confiere al teatro de Lagarce una poeticidad basada en la pseudo repetición. Esa especificidad de lenguaje, si no se traslada bien al idioma de llegada, podía convertirse en una verborrea cansina y vacía, y si se decidía cortar, peor aún porque la obra perdería todo su interés y especificidad. Por eso, en este caso preciso, traducir Lagarce era entender un pensamiento, hallando esa circularidad, con el fin de no perder el hilo conductor o mejor dicho, el bucle conductor.

Tras una delicada fase de descodificación y traducción; también he de añadir que incluso, existió una última fase. Se retocó una última vez la traducción en algunas escenas con alumnos de la UCM, cuando impartí un taller de traducción teatral en el marco del anteriormente citado festival. Actores intervinieron amablemente, prestando sus voces en la última jornada y pudimos entre todos, finalizar el trabajo. Al fin, llegaron las lecturas, los ensayos y el montaje con los actores. Cuando un texto de teatro presenta tanta riqueza y densidad textual, una única opción escénica parecía imponerse: la ausencia de movimiento corporal. Lo importante era dejar sitio a la verdadera protagonista, la palabra, optando por una rigidez corporal absoluta. Esto recalcaba y privilegiaba el espacio interpersonaje. La palabra debía corporeizarse a través de la única voz de los actores. Y así fue: un escenario depurado al máximo, con cinco sillas. Louis, La Madre, los hermanos Suzanne y Antoine y Catherine la cuñada, tenían como única restricción, no mover el cuerpo, excepto cuando estaba marcado con precisión. Los movimientos podían, o contradecir un pensamiento o subrayarlo exageradamente: un rasgo de carácter amargo podía ser marcado por una voz aguda y una rigidez postural.

\section{Conclusión}

Para concluir este testimonio, ya que se trata de una humilde experiencia más que de un estudio científico, solo quisiera decir a modo de consejo, dirigidos a aquellos que como yo, se sienten atraídos por la traducción teatral contemporánea, que lo importante es ir al teatro, para sensibilizarse con el ritmo, el espacio teatral y desarrollar así, la capacidad de imaginar una representación escénica. Desgraciadamente o afortunadamente, no hay reglas, porque cada obra y autor es un microcosmos pero si puedo decir lo que no es la traducción teatral: 
- no es una traducción literaria ya que lo que traduces no es una novela horizontal;

- no es atemporal, porque la obra de teatro vive de forma muy concreta en un tiempo espacio determinados $\mathrm{y}$, por último que

- no es un trabajo solitario y definitivo, sino una aventura colectiva donde un conjunto de personas sueñan y crean juntas. El traductor se sitúa en medio de un proyecto donde tiene que estar siempre atento y ser consciente de ese movimiento aunque haya llegado ahí, casi siempre por casualidad.

\section{Referencias bibliográficas}

Alamo, A., Les Malades. Besançon: Solitaires Intempestifs 2000.

Alonso de Santos, J.L., Manual de teoría y práctica del teatro. Madrid: Castalia, 2012.

Lagarce, J-L., Juste la fin du monde. Vol. III, Euvres complètes. Besançon: Solitaires Intempestifs 2000.

Meschonnic, H., La critique du rythme. Lagrasse: Verdier 1999.

ReISS, K., Problématiques de la traduction. Paris: Anthropos 1995

ReISS, K., / VeERMER, H-J., Grundlegung einer allgemeinen Translationtheorie. Tübingen: Max Niemeyer 1991 [1984]. 